\title{
André Gide - Paul Valéry, Correspondance 1890-1942
}

\section{Gian Luigi Di Bernardini}

\section{OpenEdition}

\section{Journals}

\section{Edizione digitale}

URL: http://journals.openedition.org/studifrancesi/5751

DOI: 10.4000/studifrancesi.5751

ISSN: 2421-5856

\section{Editore}

Rosenberg \& Sellier

\section{Edizione cartacea}

Data di pubblicazione: 1 septembre 2011

Paginazione: 452

ISSN: 0039-2944

\section{Notizia bibliografica digitale}

Gian Luigi Di Bernardini, «André Gide - Paul Valéry, Correspondance 1890-1942», Studi Francesi [Online] 164 (LV | II) | 2011, online dal 30 novembre 2015, consultato il 09 janvier 2021. URL: http:// journals.openedition.org/studifrancesi/5751 ; DOI: https://doi.org/10.4000/studifrancesi.5751

Questo documento è stato generato automaticamente il 9 janvier 2021.

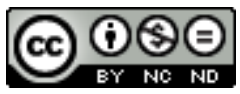

Studi Francesi è distribuita con Licenza Creative Commons Attribuzione - Non commerciale - Non opere derivate 4.0 Internazionale. 


\title{
André Gide - Paul Valéry, Correspondance 1890-1942
}

\author{
Gian Luigi Di Bernardini
}

\section{NOTIZIA}

ANDRÉ GIDE - PAUL VALÉRY, Correspondance 1890-1942, nouvelle édition établie, présentée et annotée par Peter FAWCETT, Paris, Gallimard, 2009, 991 pp.

1 La corrispondenza tra Gide e Valéry è stata pubblicata una prima volta nel 1955 da Robert Mallet. La nuova edizione integra una serie di documenti (si tratta, in particolare, di centotrentasette lettere in più rispetto alla prima edizione) apparsi, ovviamente, dopo tale data e, in particolare, le lettere di Valéry a Juliette Gide (madre dello scrittore) e a Madeleine (sua moglie), oltre alle lettere di Gide à Jeannie Valéry (moglie del poeta) e alcune risposte di Madeleine Gide.

2 Nell'Introduction (pp. 9-33) il curatore Peter Fawcett ripercorre la genesi dell'amicizia tra i due grandi scrittori, iniziata per il tramite del comune amico Pierre Louÿs, e il suo sviluppo, che condurrà ad una frequentazione progressivamente meno intensa, pur senza mai giungere a distacchi o rotture e nonostante tra i due non si sia giunti né ad una qualche forma di intimità né ad una reale ammirazione, da parte di Valéry, per l'opera di Gide.

3 Secondo l'indicazione di Peter Fawcett (Avertissement, pp. 34-35), oltre alla già citata integrazione di nuove lettere nella corrispondenza, questa edizione si segnala anche per il ricontrollo integrale dei testi sugli originali e le conseguenti correzioni di diversi errori di trascrizione. 